\title{
Local Knowledge and Management of the Royal Fern (Osmunda regalis L.) in Northern Spain: Implications for Biodiversity Conservation
}

\author{
María Molina \\ Instituto Madrileño de Investigación y Desarrollo Rural, Agrario y Alimentario, Apdo. 127, \\ 28800 Alcalá de Henares, Madrid, Spain, email: m.molina.simon@madrid.org \\ Victoria REYES-GARCÍA \\ ICREA and Institut de Ciència i Tecnologia Ambientals, Universitat Autònoma de Barcelona, \\ 08193 Bellatera, Barcelona, Spain, email: victoria.reyes@uab.cat \\ Manuel Pardo-De-Santayana \\ Departamento de Biología (Botánica). Universidad Autónoma de Madrid. c/ Darwin 2. Campus de \\ Cantoblanco, 28049 Madrid, Spain, email: manuel.pardo@uam.es \\ Centre for Pharmacognosy and Phytotherapy, The School of Pharmacy, University of London, \\ 29-39 Brunswick Square, London WC1N 1AX, UK
}

\begin{abstract}
Aвstract.-This study reports the harvesting, management, trading and use of the royal fern (Osmunda regalis) in Cantabria (Spain), where medicinal plant gathering has been mainly abandoned and nowadays only few species are still commonly gathered. We interviewed 50 adults of different age, sex, and origins to obtain information on local knowledge and management practices of royal fern. Osmunda regalis is locally considered a highly efficient remedy. The rhizome has been traditionally employed in Cantabria mainly for the treatment of bone fractures, joint disorders and rheumatic and arthritic pain. Its consumption prevails in rural areas but it is also employed in towns and cities and its demand has led to small-scale marketing. More than half of the interviewees (54\%) had only passive knowledge about their medicinal uses while the rest of informants (46\%) were consumers, collectors or sellers (22\% 'collector-consumers', 6\% 'non collector-consumers', 4\% 'collector-sellers' and 14\% 'non collector-sellers'). People from villages harvested $O$. regalis for their own consumption and expressed concern about overexploitation by a rising demand from urban areas, whereas people from cities were unaware of the ecology of the fern. The scarcity of the fern has led to rural residents to develop local management practices that contribute to the species conservation. These practices included keeping the location of the fern secret, not harvesting the complete rhizome for not killing the plant and allowing its regeneration, and cultivating the species in home-gardens. The inclusion of local knowledge in harvesting regulations might result in environmental norms accepted and internalized by the local population.
\end{abstract}

KEY Words.-Cantabria (Spain), ethnobotany, medicinal plants, resource management, conservation

Ferns have been employed for a wide variety of medicinal uses (e.g., Boom, 1985; Macía, 2004; Chang et al., 2007) but little is known on the sustainability of fern exploitation. Monitoring and regulating wild plant harvesting can contribute to biodiversity conservation and multifunctional forest management through community-based strategies that take into account the knowledge and interests of harvesters and users (Alcorn, 1993; Berkes, 2004; Moller et al., 2004; Larsen and Olsen, 2007). The proximity of customary users 
to the resource facilitates their monitoring of the species. When harvesters detect signals of declining resource levels, the impact of harvesting could be regulated by decreasing the rates and quantities extracted and by limiting the areas of plant exploitation. If wild populations cannot meet harvester demand, cultivation can be the solution for avoiding overexploitation.

In developed countries, gathering wild herbs for medicinal purposes is still practiced, although is no longer a widespread practice (Rigat et al., 2007). Wild plants collected for medicinal purposes include weeds (e.g., Malva sylvestris L.) and other common species such as Rosmarinus officinalis L. (Pardo-deSantayana and Morales, 2005), and collection is mainly performed for domestic consumption. Research shows that the collection of medicinal plants in developed countries also affects some scarce plants and is also done for commercial purposes. Since the harvesting of wild medicinal plants in developed countries is not strictly regulated, the gathering and commercialization of these species are difficult to track, which hampers the ability to predict situations of overexploitation (Lange, 1998).

Here we study the harvesting of the royal fern (Osmunda regalis L., Osmundaceae), a subcosmopolitan fern widely distributed in some tropical and temperate regions. The royal fern is a predominantly western and southern species within Europe (Page, 1996). It grows in wetland habitats of north, middle, and west areas of the Iberian Peninsula, where it is mainly confined to riverbanks (Fig. 1a), especially in Atlantic alder groves (Alnus glutinosa (L.) Gaertn.) The royal fern has a long history of medicinal use (e.g., Culpeper, 1653; Austin, 2004). In the north of Spain (Galicia, Asturias, and Cantabria), the fern, locally known as antojil, has traditionally been employed to set broken bones, mitigate muscular ache, and treat muscle-skeletal, respiratory, and digestive disorders. Locally, the fern is prepared by maceration of the middle part of the rhizome with white wine. It is made into a bitter and mucilaginous beverage known as 'antojil wine' (Molina, 2006) (Fig. 1b,c). Osmunda regalis is not listed in modern Pharmacopoeias (e.g., Real Farmacopea Española, 3rd ed. 2005; European Pharmacopoeia, 6th ed. 2007) or scientific phytotherapy books (e.g., ESCOP, 2003; Vanaclocha and Cañigueral, 2003), but Spanish regional administrations recognize that the species is gathered to be used as medicine for both domestic consumption and smallscale marketing (Gobierno de Cantabria, 2005).

In some regions of Spain (i.e., Catalonia, Basque Country, and Castilla-La Mancha), O. regalis is rare and is therefore catalogued as threatened (i.e., 'strictly protected', 'rare', and 'of special interest' respectively; Devesa and Ortega, 2004). In other regions, where the species has a larger range but is still not abundant (e.g., Cantabria, Asturias; Loriente, 1999), its harvesting is not regulated.

In this research, we assess individual knowledge and practices related to the medicinal use, management, and commercialization of Osmunda regalis in a region where its harvesting is not regulated (Cantabria, Spain). Assessing individual level variation in knowledge and practices of a wild medicinal plant can help predict future harvesting trends. 


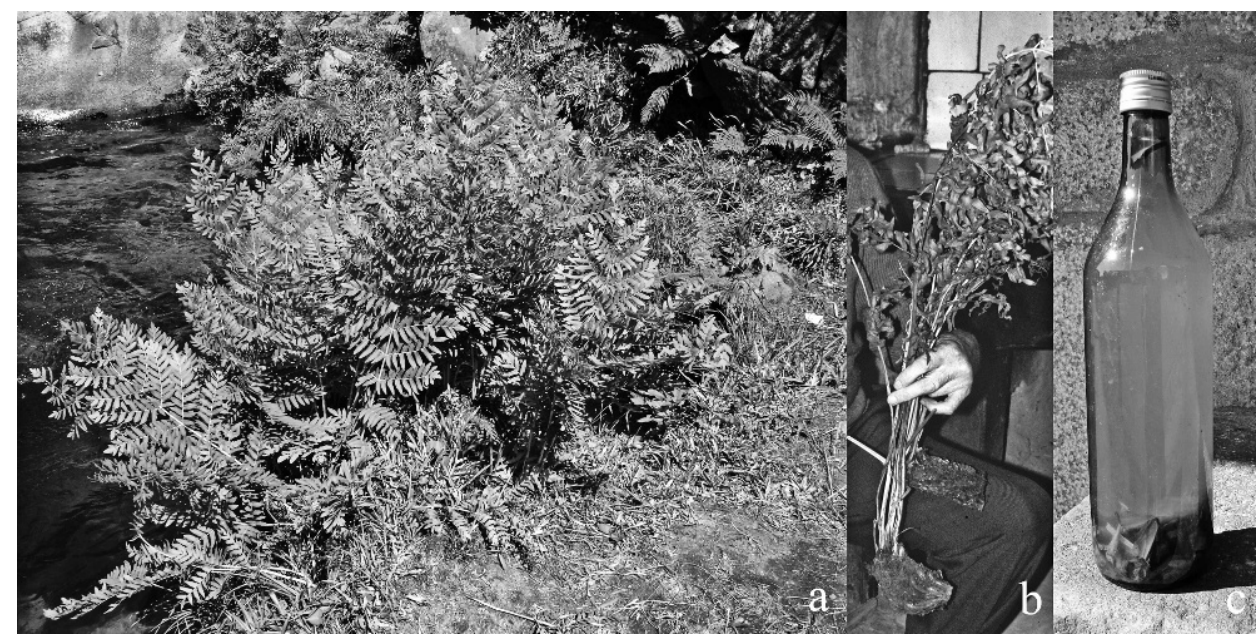

FIG. 1. a) Royal fern in his natural environment. b) Informant showing two harvested rhizomes. c) Antojil wine.

\section{MethoDs}

We carried out five ethnobotanical fieldtrips from August 2005 to April 2006. We conducted semi-structured interviews to obtain information on local knowledge and practices regarding (1) medicinal uses (including processing and administration) and commercialization of $O$. regalis and (2) identification, habitat, and harvesting practices.

We used a quota sampling strategy to select informants of different age and sex, from rural and urban areas. People who did not know any medicinal use of the fern were not included in the study. We used snowball sampling to contact hard-to-find key informants such as sellers and gatherers (Bernard, 2006). Our final sample included 50 adults from 21 localities. The sample included men $(66 \%)$ and women $(34 \%)$ between 30 and 90 years of age (avg $=53$ years, $\mathrm{SD}=17.14)$. Thirty six percent of the informants lived in localities with over 10,000 inhabitants (urban); 22\% lived in villages at less than $20 \mathrm{~km}$ from the nearest urban settlement (nearby-rural); and $42 \%$ lived in villages farther than $20 \mathrm{~km}$ from the nearest urban settlement (faraway-rural).

To analyze the individual differences in knowledge and practices of $O$. regalis, we divided informants into five categories: A. Passive knowledge holder: Informants who knew at least one medicinal use of $O$. regalis, but who had never used the species; B. Non collector-consumer: Informants who had used the species, but had never collected or prepared it by themselves; C. Collector-consumer: Informants who had collected or prepared the species for domestic but not for commercial purposes; D. Collector-seller: Informants who had collected or prepared the species with commercial purposes; E. Non collector-seller: Informants who had commercialized 'antojil wine', but had never harvested or processed the plant. 
TABle 1. Medicinal uses of Osmunda regalis in Cantabria. \#Inf.: Number of informants who mentioned each use.

\begin{tabular}{lclr}
\hline \multicolumn{1}{c}{ Medicinal use-category } & \# Inf. & Medicinal use-category & \# Inf. \\
\hline Muscle-skeletal System & $\mathbf{5 0}$ & Others uses & $\mathbf{1 2}$ \\
Bone regeneration & 31 & Tonic & 6 \\
Unspecified bone disorders & 24 & Digestive disorders & 5 \\
Joint or vertebral pain & 13 & Respiratory disorders & 3 \\
Traumatism & 8 & Child disorders & 1 \\
Muscular disorders & 2 & & \\
\hline
\end{tabular}

\section{RESULTS}

Local knowledge.-As in other regions, in Cantabria, antojil has been traditionally employed for muscle-skeletal disorders $(100 \%$ of the informants mentioned this use-category), including bone fractures, osteoporosis and bone decalcification (62\%), joint and vertebral disorders such as rheumatic, arthritic, arthrosic or back pain (26\%), traumatic injuries such as bruises, dislocations, or sprains $(16 \%)$ and muscular injuries or pains $(4 \%)$. The category 'unspecified bone disorders' (48\%) includes muscle-skeletal conditions that were not specifically described by informants. It is also used as tonic, against rickets, digestive and respiratory disorders (Table 1). Moreover, $26 \%$ of informants reported the veterinary use of antojil for setting bone fractures and broken horns. Its cultural relevance is reflected in the local legend that says it can stick together a piece of meat that was previously cut in small pieces. Informants (16\%) reported that they had successfully used the fern after therapies prescribed by doctors had failed. Although most doctors do not approve the use of the herbal remedy, $6 \%$ of the interviewees said that there are doctors that even recommend it for bone regeneration. Additionally a few informants $(10 \%)$ reported that other healthcare professionals such as ostheopaths, medical assistants, physiotherapists and traditional healers recognize the healing virtues of antojil.

In Cantabria, the most usual remedy made out of $O$. regalis is antojil wine, which is the only remedy made out of antojil that is commercialized. The preparation must be drunk daily before breakfast until the patient has drunk one or two $750 \mathrm{ml}$ bottles, although chronic patients take it for years. Antojil wine is mainly consumed by men. Its intake is not recommended for pregnant women and women of childbearing age and $18 \%$ mentioned that the remedy is considered abortive. They said that if you consume antojil wine "the fetus sticks to the womb", or "does not allow the womb to distend during birth". Moreover girls should not take the remedy since it is said that the "pelvis could weld before it should". Among men, antojil wine is mainly consumed by sportsmen and the elderly.

Osmunda regalis is consumed in rural areas but also in towns and cities. Most people in our sample that had used the remedy did not know how to prepare antojil wine. The demand for antojil wine has led to small-scale 
informal marketing that originated at least 25 years ago. Antojil wine is commercialized through two different channels. Some people buy the remedy directly from the villagers who gather the plant and elaborate the remedy at home. The remedy can also be obtained in herbal shops or street-markets in cities. However, antojil wine is not a licensed product and some sellers are concerned about its marketing. In fact, two herbal shop sellers reported that they did not commercialize the remedy for this reason.

Harvesting practices.-Interviewees mentioned that $O$. regalis grows in small stream banks, rocky and steep slopes, and in north-facing places. According to informants, the rhizome from a mature specimen can measure up to $8 \mathrm{~cm}$ long. A new rhizome takes about 10 years to regenerate if harvesting is not destructive, i.e. cutting without uprooting the whole rhizome. Informants knew that the fern is not abundant in the region. As many as $36 \%$ of the informants associated the scarcity of the fern with bad harvesting practices and overexploitation. Several informants (12\%) also reported that the abundance of the species had declined over the last decades.

In the study region, the rhizome is mainly harvested in remote zones and only by men. The rhizome is harvested during the dormant season, between November and January, using a hoe. Four harvesters reportedly know how to collect the rhizome without killing the plant. Four informants told us that it is prohibited to gather the species, although no law regulates its collection in Cantabria. Because of the perceived scarcity of the fern, rural habitants have developed local management practices that contribute to the conservation of the species. Local management practices include (1) harvesting without uprooting the whole rhizome, to allow plant restoration, (2) not sharing harvesting locations to avoid their destruction and to preserve them for later harvest, (3) harvesting from the neighboring province of Asturias where the fern is more abundant, and (4) cultivating the fern in home-gardens. Although only one informant grew the fern in his garden, eight interviewees said that they knew people that cultivated it.

Informant's distribution in the plant exploitation network.-More than half of the interviewees (54\%) had only passive knowledge about the medicinal uses of antojil, i.e. they knew about antojil's medicinal properties, but had never consumed, collected, or sold it (Fig. 2). The category of 'passive knowledge holder' included male and female informants from the three different settlement origins, mainly within the 41-50 age group (Fig. 3). Only four of the 27 'passive knowledge holders' knew how to identify the plant and could be considered potential harvesters (Table 2).

The remaining $46 \%$ of informants were involved in the plant exploitation network as consumers, harvesters, or sellers: $22 \%$ of the sample fell in the category 'collector-consumers', $4 \%$ in the category 'collector-sellers', $14 \%$ in the category 'non collector-seller', and 6\% in the category 'non-collector consumers' (Fig. 2).

All the informants in the two categories of consumers ('collector-consumers' and 'non collectors-consumers') were from rural origins (Fig. 4, 5). 'Noncollector consumers' were mainly nearby-rurals ranging between 40 and 70 


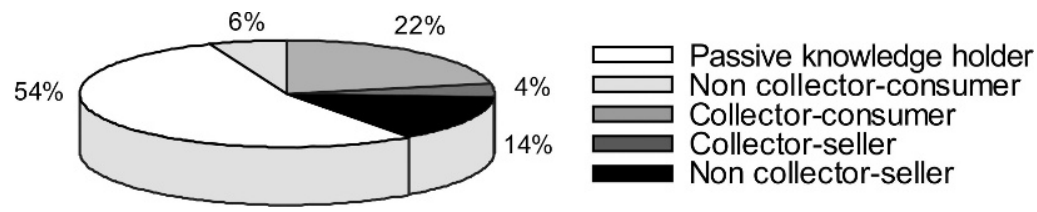

FIG. 2. Percentage of informants included in the five categories established.

years of age (avg $=55$ years) whereas 'collector-consumers' were mainly faraway-rurals and elders (avg $=67$ years). Collectors showed the highest knowledge about the ecological characteristics of the plant.

Sellers represented $18 \%$ of the informants and lived in urban settings (Fig. 6, 7). Fourteen percent of sellers were 'non collector-sellers', a group that included herbal shop and street-market sellers. The group included young women (Fig. 7). We only interviewed two 'collector-sellers', both restaurant owners, who had a key role in the trading circuit. 'Collector-sellers' had extensive local knowledge of the fern and a wide customer net. They even mailed the product to other provinces (Table 2).

\section{Discussion}

We organize the discussion around two main topics that emerge from our findings. First, we discuss the persistence of the knowledge and medicinal use of a wild species. Second, we evaluate the distribution of harvesting and commercialization practices of $O$. regalis and its implications for conservation.

Our data suggest that antojil wine is still commonly known and used in Cantabria where it is considered a highly efficient remedy. We found that male and female informants from all origins and age groups reported knowing the medicinal properties of $O$. regalis (Fig. 3). The presence of young informants, especially in the categories 'passive knowledge holders' and 'non-collector

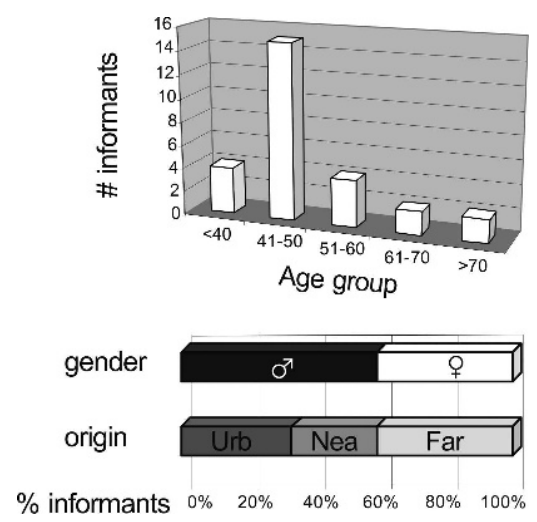

FIG. 3. Informant's distribution by sex, age group, and origin among 'passive knowledge holders'. Urb: urban; Nea: nearby-rural; Far: faraway-rural. 


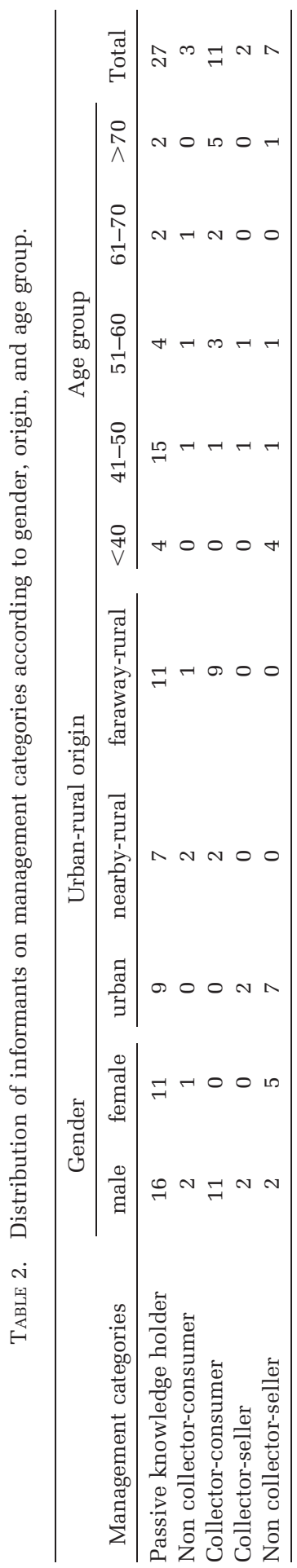




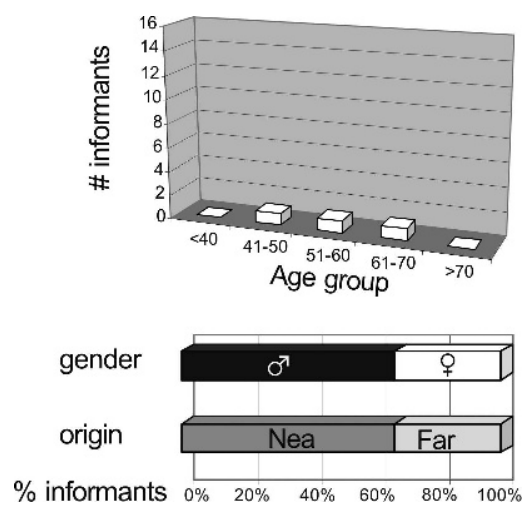

FIG. 4. Informant's distribution by sex, age group, and origin among 'non collector-consumers'. Urb, Nea, Far: see Fig. 3.

sellers' suggests that ethnobotanical knowledge of antojil is not threatened. Our finding meshes with previous studies in the region that describe the marketing of other medicinal plants (i.e., Chamaemelum nobile (L) All. and Sideritis hyssopifolia L.) locally preferred to pharmaceutical medicines (Pardode-Santayana, 2004). The results also agree with research among indigenous populations that shows that market economy is not necessarily linked to the loss of local knowledge of wild plants (e.g., Zarger and Stepp, 2004; ReyesGarcía et al., 2007).

We found that most collectors were people over 50 years of age who lived in remote villages in direct contact with the resource (Fig. 5). Besides collectors, only four informants had the knowledge for harvesting the rhizome and preparing antojil wine. Our data also highlight that most sellers were young men and women living in towns and cities who lacked ecological knowledge of antojil (Fig. 7). Consumers were from urban and nearby-rural origins and generally also lacked the ecological knowledge of the plant. Our data suggest

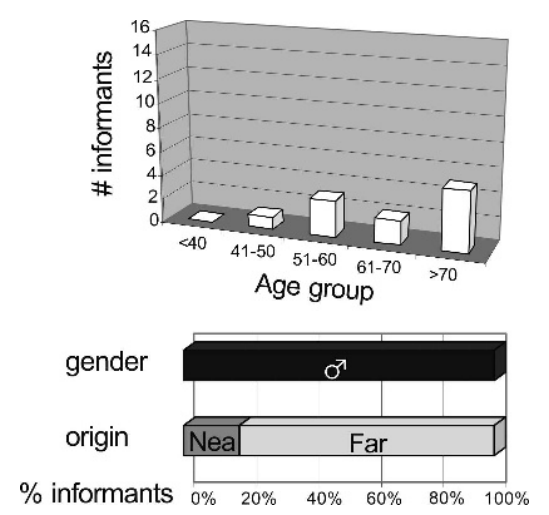

FIG. 5. Informant's distribution by sex, age group, and origin among 'collector-consumers'. Urb, Nea, Far: see Fig. 3. 


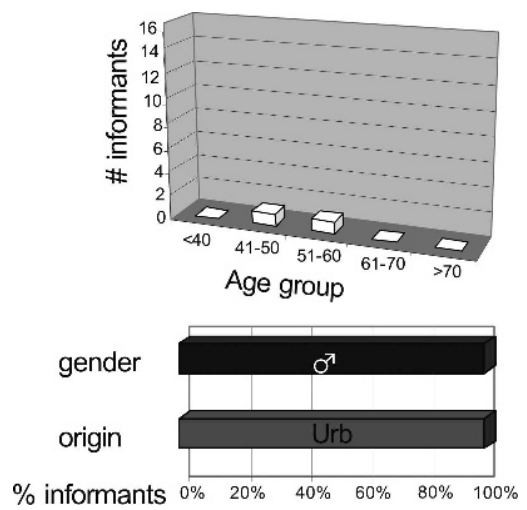

FIG. 6. Informant's distribution by sex, age group, and origin among 'collector-sellers'. Urb, Nea, Far: see Fig. 3.

that urban consumption of antojil might increase over the next decades due to the development of a wide urban customer network and to the presence of an aging population. The dissociation between the consumption of a remedy made from an unprotected wild plant and the ecological knowledge of the plant might have important implications for the conservation of the species. Unaware of harvesting practices, urban consumers and sellers do not understand the risk of overexploitation associated with the rising demand.

We found that all collectors expressed concern about the effects of destructive harvesting generated by a rising demand. Moreover, three 'collector consumers' expressed concern over the fact that some collectors and sellers are only driven by economic incentives and do not care about the sustainability of the resource. Informants perceive economic interests as a risk for antojil's conservation and for the quality of the marketed medicinal products because some traders are diluting antojil wine which might destroy the efficacy of the

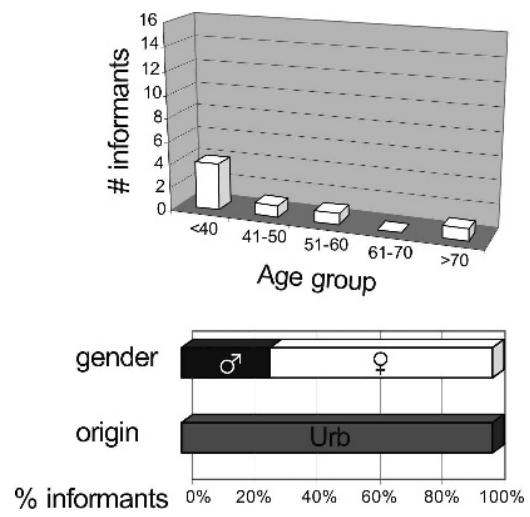

FIG. 7. Informant's distribution by sex, age group, and origin among 'non collector-sellers'. Urb, Nea, Far: see Fig. 3. 
remedy. The concerns expressed by informants are similar to those reported in other case studies, when the commercialization of a medicinal plant has lead to its overexploitation (Botha et al., 2004; Pardo-de-Santayana et al., 2005).

Results from this research suggest that local ecological knowledge and practices are still alive in rural areas of developed countries, and that local harvesters are interested in the sustainable use of wild resources. This offers an opportunity to design management programs where local people participate actively encouraging the acceptance and internalization of environmental norms (Pardo-de-Santayana and Morales 2001).

\section{ACKNOWLEDGMENTS}

We are grateful to all the people who kindly shared their knowledge and time. We thank J. Tardío, R. Morales, S. González, L. Aceituno and two anonymous reviewers for revising and improving the manuscript.

\section{Literature Cited}

Alcorn, J. B. 1993. Indigenous peoples and conservation. Conserv. Biol. 7:424-426.

Austin, D. F., ed. 2004. Florida Ethnobotany. CRC Press, Florida.

Berkes, F. 2004. Rethinking community-based conservation. Conserv. Biol. 18:621-630.

Bernard, H. R. 2006. Research methods in Anthropology. Qualitative and quantitative approaches. Fourth edition. Altamira Press, Walnut Creek.

Bоoм, B. M. 1985. Ethnopteridology of the Chacobo Indians in Amazonian Bolivia. Amer. Fern J. 75:19-21.

Botha, J., E. T. E. Witkowski, C. M. Shackleton and D. H. K. Fairbanks. 2004. Socio-economic differentiation in the trade of wildlife species for traditional medicines in the Lowveld, South Africa: implications for resource management initiatives. Int. J. Sust. Dev. World Ecol. 11:280-297.

Chang, H. C., G. J. Huang, D. C. Agrawal, C. L. Kuo, C. R. Wu and H. S. Tsay. 2007. Antioxidant activities and polyphenol contents of six folk medicinal ferns used as "Gusuibu”. Bot. Stud. 48:397-406.

CulPEPER, N. 1653 (1995). Culpeper's complete herbal. Wordsworth, Ware, Hertfordshire.

Devesa, J. A. and A. Ortega. 2004. Especies vegetales protegidas en España: plantas vasculares. Ministerio de Medio Ambiente, Madrid.

ESCOP (European Scientific Cooperative on Phytotherapy), eds. 2003. ESCOP Monographs. The scientific foundation for herbal medicinal products. ESCOP, Exeter. Thieme, Stuttgart, New York.

Gobierno de Cantabria. 2005. Plan Forestal de Cantabria. Plan Estratégico Regional sobre el Medio Natural. Documento operativo. Dirección General de Montes y Conservación de la Naturaleza. Available from http://www.dgmontes.org/acrobat/PFC_PARLAMENTO_completo.pdf (accessed April 2008).

LANGe, D. 1998. Europe's medicinal and aromatic plants: their use, trade and conservation. Traffic International, Cambridge, United Kingdom.

LARSEN, H. O. and C. S. OlsEN. 2007. Unsustainable collection and unfair trade? Uncovering and assessing assumptions regarding Central Himalayan medicinal plant conservation. Biodivers. Conserv. 16:1679-1697.

LoRIENTE, E. 1999. Ecología y corología de las plantas espontáneas de Cantabria I (PteridophytaGimnospermae). Tantín, Santander.

Macía, M. J. 2004. A comparison of useful pteridophytes between two Amerindian groups from Amazonian Bolivia and Ecuador. Amer. Fern J. 94:39-46. 
Molina, M. 2006. Conocimiento y manejo de Osmunda regalis L. en la medicina popular de Cantabria. BSc Thesis. Department of Biology. Universidad Autónoma de Madrid, Madrid.

Moller, H., F. Berkes, P. O. Lyver and M. Kislalioglu. 2004. Combining science and traditional ecological knowledge: monitoring populations for co-management. Ecol. Soc. 9(3):2. Available from http://www.ecologyandsociety.org/vol9/iss3/art2/ (accessed April 2008).

PAGE, C. N. 1996. The ferns of Britain and Ireland. 2nd edition. Cambridge, University Press, Cambridge, Massachussets.

Pardo-de-Santayana, M. 2004. Guía de las plantas medicinales de Cantabria. Salud y tradición popular. Estvdio, Santander.

Pardo-de-Santayana, M. and R. Morales. 2001. Patrimonio natural, usos tradicionales y conservación. Quercus 189:64-65.

Pardo-de-Santayana, M. and R. Morales. 2005. Fitoterapia popular. Plantas medicinales de uso tradicional en la Península Ibérica. Rev. Fitoterapia 5(1):227-228.

Pardo-de-Santayana, M., J. Tardío and R. Morales. 2005. The gathering and consumption of wild edible plants in Campoo (Cantabria, Spain). Int. J. Food Sci. Nutr. 56:529-542.

Reyes-García, V., V. Vadez, T. Huanca, W. R. Leonard and T. McDade. 2007. Economic development and local ecological knowledge: A deadlock? Quantitative research from a native Amazonian society. Hum. Ecol. 35:371-377.

Rigat, M., M. A. Bonet, S. Garcia, T. Garnatje and J. Vallès. 2007. Studies on pharmaceutical ethnobotany in the high river Ter valley (Pyrenees, Catalonia, Iberian Peninsula). J. Ethnopharmacol. 113:267-277.

Vanaclocha, B. and S. Cañigueral, eds. 2003. Fitoterapia, vademécum de prescripción. 4th edition. Elsevier - Masson, Barcelona.

Zarger, R. and J. R. STEPP. 2004. Persistence of botanical knowledge among Tzeltal Maya children. Curr. Anthropol. 45:413-418. 